Gut and Liver, Vol. 10, No. 5, September 2016, pp. 757-763

\title{
Antral or Pyloric Deformity Is a Risk Factor for the Development of Postendoscopic Submucosal Dissection Pyloric Strictures
}

Kyu Yeon Hahn ${ }^{1}$, Jun Chul Park ${ }^{1}$, Hyun Jik Lee ${ }^{2}$, Chan Hyuk Park ${ }^{3}$, Hyunsoo Chung ${ }^{1}$, Sung Kwan Shin ${ }^{1}$, Sang Kil Lee ${ }^{1}$, and Yong Chan Lee ${ }^{1}$

${ }^{1}$ Division of Gastroenterology, Department of Internal Medicine, Severance Hospital, Institute of Gastroenterology, Yonsei University College of Medicine, '2Division of Gastroenterology, Department of Internal Medicine, Incheon St. Mary's Hospital, The Catholic University of Korea College of Medicine, and ${ }^{3}$ Department of Internal Medicine, Hanyang University Guri Hospital, Hanyang University College of Medicine, Seoul, Korea

Background/Aims: Surgeons must be aware of risk factors for strictures before performing endoscopic submucosal dissection (ESD), to enable early interventions to prevent severe strictures. Methods: This study was a single-center retrospective study. We reviewed the clinical data of patients who has undergone gastric ESD from January 2007 to December 2012. Results: Among the 3,819 patients who had undergone gastric ESD, 11 patients (7.2\%) developed pyloric strictures and received successful endoscopic balloon dilation. Significant differences were noted between the patients without and with post-ESD strictures for pretreatment of antral or pyloric deformities (46.4\% vs $81.8 \%$ ), the proportion of extension to the lumen circumference (>3/4, 9.4\% vs $54.5 \%)$, the longitudinal extent of mucosal defects $(27.9 \pm 10.1 \mathrm{~mm}$ vs $51.5 \pm 10.8 \mathrm{~mm}$ ), and post-ESD bleeding ( $2.9 \%$ vs $27.3 \%$ ). Multivariate analysis revealed that pretreatment antral or pyloric deformities (odds ratio [OR], 30.53; 95\% confidence interval $[\mathrm{Cl}$ ], 1.476 to $631.565 ; \mathrm{p}=0.027$ ), larger longitudinal extent of mucosal defects (OR, 1.20; $95 \% \mathrm{Cl}, 1.074$ to 1.340; $p=0.001$ ), and circumferential extension of $\geq 3 / 4$ (OR, 13.69; $95 \% \mathrm{Cl}, 1.583$ to 118.387 ; $\mathrm{p}=0.017$ ) were independent risk factors for post-ESD stricture. Conclusions: Antral or pyloric deformities, sub-circumferential resection over more than $75 \%$ of the circumference and greater longitudinal extent of mucosal defects are independent risk factors for post-ESD stricture. (Gut Liver 2016;10:757-763)

Key Words: Antral deformity; Pyloric deformity; Endoscopic submucosal dissection; Post-endoscopic submucosal dissection stricture

\section{INTRODUCTION}

Endoscopic resection (ER) for gastric tumors is minimally invasive, respects the quality of life, and is similar in efficacy to surgery. ${ }^{1}$ Currently, endoscopic submucosal dissection (ESD) is established as standard treatment in patients with gastric tumor, including early gastric cancer (EGC) who have a negligible risk of lymph node metastasis. ${ }^{2-5}$ Because ER, and especially ESD, allows en bloc resection, ER can ensure accurate histopathological examination and reduce the risk of local recurrence.

Although the safety of ESD has been demonstrated, it is technically challenging and requires a well-trained endoscopist. ESD is also associated with massive bleeding, perforation, and stricture. Bleeding and perforation are the most common complications and tend to occur during or within 24 to 48 hours after the procedure, whereas post-ESD strictures occur several weeks after intervention. Because post-ESD stricture can cause severe obstructive symptoms, including nausea, vomiting, dysphagia, and weight loss, awareness of the risk factors for postESD stricture prior to the procedure is important so that early interventions, including endoscopic balloon dilatation and local steroid injection, can be performed. In previous studies, resected circumference, longitudinal diameter, and location of the lesion have been associated with post-ESD strictures. ${ }^{6,7}$ Among these, circumferential extension over 75\% is a strong risk factor for post-ESD stricture. ${ }^{6,7}$ However, clinically, in the presence of antrum or pyloric deformity caused by ulcer scarring before ESD, post-ESD stricture occurs frequently, even if the circumferential extension is $<75 \%$. Therefore, we performed this study to investigate whether antral or pyloric deformity is a significant risk

Correspondence to: Jun Chul Park

Division of Gastroenterology, Department of Internal Medicine, Severance Hospital, Institute of Gastroenterology, Yonsei University College of Medicine, 50 Yonsei-ro, Seodaemun-gu, Seoul 03772, Korea

Tel: +82-2-2228-2272, Fax: +82-2-2393-6884, E-mail: junchul75@yuhs.ac

Received on October 9, 2015. Revised on December 13, 2015. Accepted on December 28, 2015. Published online June 13 , 2016 pISSN 1976-2283 eISSN 2005-1212 http://dx.doi.org/10.5009/gnl15511

@) This is an Open Access article distributed under the terms of the Creative Commons Attribution Non-Commercial License (http://creativecommons.org/licenses/by-nc/4.0) which permits unrestricted non-commercial use, distribution, and reproduction in any medium, provided the original work is properly cited. 
factor for development of post-ESD stricture.

\section{MATERIALS AND METHODS}

\section{Patients}

This study is a single center, retrospective study. We retrospectively reviewed a prospective database at Severance Hospital, Yonsei University College of Medicine, Seoul, Korea. From January 2007 to December 2012, a total 3,819 patients with 1,642 EGC and 1,747 adenoma underwent ESD. Of these, 150 cases of gastric tumors were at the prepylorus or pylorus. Eleven of the 150 patients (7.3\%) developed pyloric strictures. The median follow-up period was 22.3 months. After ESD, patients were followed in an outpatient clinic, and endoscopy was routinely performed 2 to 3 months later. In the presence of obstructive symptoms, EGD was performed earlier. All patients provided informed consent before undergoing the procedure, and the Institutional Review Board of Severance Hospital approved this study.

\section{ESD procedures}

All ESDs were performed under conscious sedation that was achieved with intravenous midazolam and/or propofol. A standard single-channel endoscope (GIF-Q260J or GIF-H260Z; Olympus, Tokyo, Japan) was used. After identifying the target lesion, dots were marked circumferentially at about $5 \mathrm{~mm}$ lateral to the margin of the lesion using a needle knife (KD-10Q; Olympus) or argon plasma coagulation (Erbe Elektromedizin, Tübingen, Germany). Epinephrine (1:10,000 dilution) was then injected into the submucosal layer using a 21-gauge needle to lift the lesion from the muscle layer. Circumferential mucosa was excised outside the dots, and an additional submucosal injection was made. Finally, direct dissection of the submucosal layer was performed using an insulated-tip knife (KD-610L; Olympus). Endoscopic hemostasis with specialized hemostatic forceps (FD-410LR; Olympus) was performed, as needed.

\section{Definitions}

Prepyloric lesion was defined as any mucosal defect after
ESD was located within $2 \mathrm{~cm}$ from the pylorus ring. PostESD stricture was defined as a pyloric stricture that could not be traversed with a standard 1-cm endoscope. Patients were divided into two groups, namely those with or without a postESD stricture. All patients with a post-ESD stricture underwent endoscopic balloon dilatation. Between the two groups, age, sex, concomitant disease, location of lesion and macroscopic type, depth of invasion, longitudinal extent of mucosal defect, resection range including the pyloric ring, and antral or pyloric deformity, were compared. Antral or pyloric deformity was defined as a distortion or narrowing of antrum usually caused by peptic ulcer scarring or prominent folds. ${ }^{8}$ All endoscopic images were reviewed by two expert endoscopists and the presence of the antral or pyloric deformity was judged. We divided antral or pylorus deformity into two groups, distortion dominant or narrowing dominant group. We defined distortion dominant type when the whole pylorus ring could not be seen in a forwarding endoscopic view because of severe distortion caused by prominent folds or hypertrophy of the antral pyloric musculature in prepylorus (Fig. 1A). Narrowing dominant type was defined when antrum and prepylorus lesion became narrow abruptly toward pylorus ring caused by ulcer scarring or pyloric hypertrophy (Fig. 1B). The longitudinal extent of mucosal defect was investigated based on gross pathology reports of the resected specimen. Acute complications were defined as adverse events within 48 hours after ESD. Bleeding was defined as an event such as hematemesis or melena, and adverse event requiring transfusion or endoscopic hemostasis. Perforation included a definite gastric wall defect during ESD and microperforation diagnosed by free air in X-ray after ESD. An attending gastroenterologist noted the presence of antral or pyloric deformity before ESD.

\section{Treatment of post-ESD stricture patients}

Patients with symptoms (nausea, vomiting, and dysphagia) caused by the pyloric stricture were treated by endoscopic balloon dilation performed under endoscopic and fluoroscopic guidance by experienced endoscopists. All procedures were performed under conscious sedation using intravenous midazolam
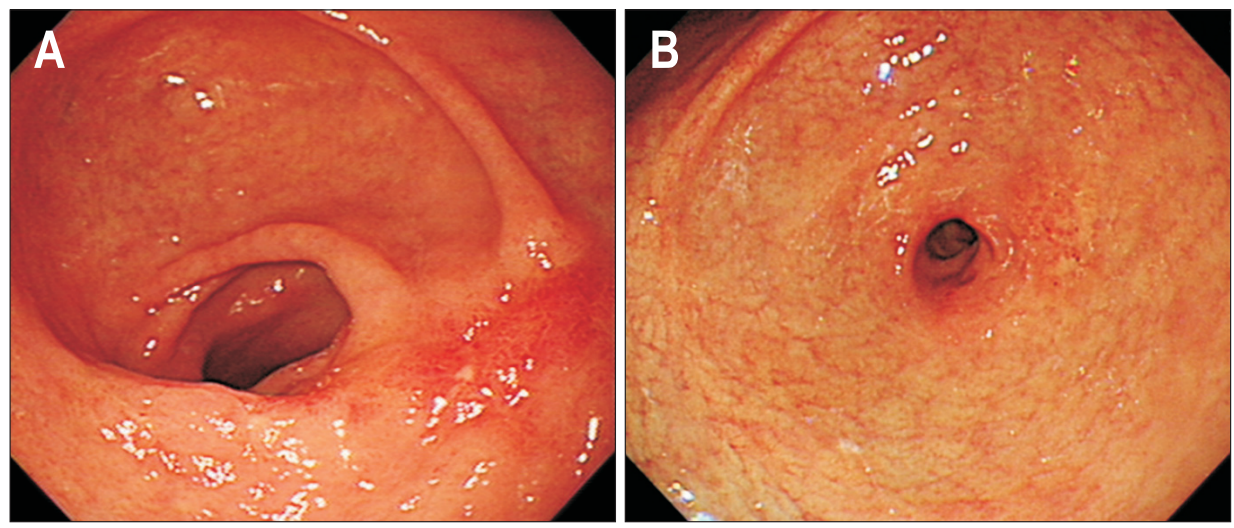

Fig. 1. Endoscopic images of antral/ pyloric deformities. A high-grade dysplasia lesion was present in the distal antrum. (A) Distortion dominant type: the whole pylorus ring could not be seen in the forward endoscopic view because of severe distortion of the prepylorus. (B) Narrowing dominant type: the distal antrum and prepylorus lesion narrowed abruptly toward the pylorus ring. 
and/or propofol. A forward-viewing esophagogastroduodenoscope (GIF-H260; Olympus) was inserted through the mouth, and a 12 to $15 \mathrm{~mm}, 15$ to $18 \mathrm{~mm}$, or 18 to $20-\mathrm{mm}$ wire-guided balloon dilator (CRE Wire-Guided Balloon Dilatation Catheter; Boston Scientific, Marlborough, MA, USA) was inserted through the working channel of the endoscope. The balloon was advanced across the stricture and by injecting water under controlled pressure, was dilated to progressively increase the diam- eter of the stricture. The diameter size and ballooning time were determined by the endoscopist and depended on the endoscopic assessment of the luminal width. After deflation, the procedure was ended after examining the patency of the pylorus by administering a contrast agent (Gastrografin; Bayer, Seoul, Korea) under fluoroscopy.

In addition, local triamcinolone acetonide (TCA) (50 mg/5 $\mathrm{mL}$; Dongkwang Pharmaceutical Co., Seoul, Korea) injection

Table 1. Baseline Characteristics and Risk Factors for Post-ESD Stricture

\begin{tabular}{|c|c|c|c|c|}
\hline \multirow{2}{*}{ Characteristic } & \multicolumn{4}{|c|}{ Post-ESD stricture } \\
\hline & Total $(n=150)$ & None $(n=139)$ & Present $(n=11)$ & p-value \\
\hline Age, yr & $69.6 \pm 10.0$ & $69.3 \pm 10.2$ & $73.6 \pm 6.0$ & 0.166 \\
\hline Sex & & & & 0.122 \\
\hline Male & $139(92.7)$ & $97(69.8)$ & $10(90.9)$ & \\
\hline Female & $11(7.3)$ & $42(30.2)$ & $1(9.1)$ & \\
\hline \multicolumn{5}{|l|}{ Concomitant disease } \\
\hline Hypertension & $60(40.0)$ & 55 (39.6) & $5(45.5)$ & 0.701 \\
\hline Diabetes mellitus & $22(14.7)$ & $22(15.8)$ & 0 & 0.153 \\
\hline Chronic renal failure & $2(1.3)$ & $2(1.4)$ & 0 & 0.689 \\
\hline Hepatitis & $4(2.7)$ & $3(2.2)$ & $1(9.1)$ & 0.169 \\
\hline Location of lesion & & & & 0.548 \\
\hline Lesser curvature & $52(34.7)$ & $48(34.5)$ & $4(36.4)$ & \\
\hline Anterior wall & $50(33.3)$ & $48(34.5)$ & $2(18.2)$ & \\
\hline Greater curvature & $26(17.3)$ & 24 (17.3) & $2(18.2)$ & \\
\hline Posterior wall & $22(14.7)$ & 19 (13.7) & $3(27.3)$ & \\
\hline Lesion macroscopic type & & & & 1.000 \\
\hline Elevated & $118(78.7)$ & $109(78.4)$ & $9(81.8)$ & \\
\hline Flat or depressed & $32(21.3)$ & $30(21.6)$ & $2(18.2)$ & \\
\hline Histology & & & & 0.741 \\
\hline Adenoma & $103(68.7)$ & $96(69.1)$ & 7 (63.6) & \\
\hline Adenocarcinoma & 47 (31.3) & $43(30.9)$ & $4(36.4)$ & \\
\hline Well differentiated & & $30(21.6)$ & $3(27.3)$ & \\
\hline Moderately differentiated & & $9(6.5)$ & $1(9.1)$ & \\
\hline Poorly differentiated & & 0 & 0 & \\
\hline Signet ring cell & & $1(0.7)$ & 0 & \\
\hline Carcinoma in situ & & $3(2.2)$ & 0 & \\
\hline Depth of invasion & & & & 0.586 \\
\hline Carcinoma in situ & $3(6.4)$ & $3(7.0)$ & 0 & \\
\hline Mucosal & $38(80.9)$ & $35(81.4)$ & $3(75.0)$ & \\
\hline Submucosal & $6(12.8)$ & $5(11.6)$ & $1(16.7)$ & \\
\hline En bloc resection & $130(86.7)$ & 122 (87.8) & $8(72.7)$ & 0.166 \\
\hline Curative resection & $135(90.0)$ & $127(91.4)$ & 8 (72.7) & 0.082 \\
\hline \multicolumn{5}{|l|}{ Acute complication } \\
\hline Bleeding & $7(4.7)$ & $4(2.9)$ & $3(27.3)$ & 0.009 \\
\hline Perforation & $3(2.0)$ & $2(1.4)$ & $1(9.1)$ & 0.206 \\
\hline
\end{tabular}

Data are presented as median \pm SD or number $(\%)$. ESD, endoscopic submucosal dissection. 
was performed 1 to 2 days after ESD according to endoscopist's judgement. Local TCA, 50 to $100 \mathrm{mg}$ was injected into the submucosal layer of post-ESD ulcer margin using a 21-gauge needle.

\section{Statistical analysis}

Statistical tests to compare the results included Student ttest, chi-square test, Fisher exact test, and multivariate analysis. Mann-Whitney test was done for the nonparametric variable. A $p<0.05$ was considered statistically significant. All statistical analyses were performed using SPSS version 18.0 for Windows (SPSS Inc., Chicago, IL, USA).

\section{RESULTS}

\section{Baseline characteristics and clinical factors associated with pyloric stricture after ESD}

The baseline characteristics of the study population are summarized in Table 1. The median age of patients was 69.6 years, and the male/female ratio was 2.49:1 (107/43). The median age, ratio of sex, concomitant disease (hypertension, diabetes mellitus, chronic kidney disease, or hepatitis), location of lesions and the macroscopic type of the lesion were not significantly different between the two groups. A total of 103 patients had undergone ESD for gastric adenoma, and 47 patients for EGC. There were no significantly differences in histological findings and depth of invasion between the two groups. En-bloc resection rate and curative resection rate was not significantly different between two groups. Among acute complications, the rate of post-ESD bleeding was higher in stricture group (2.9\% vs $27.3 \%, p=0.009$ ). Factor associated with ESD procedure was summarized in Table 2. Type of antral deformity and resection range if the pyloric ring was included were not significantly different between the two groups. Significant differences in the presence of pretreatment antral or pyloric deformity (46.8\% vs $81.8 \%$ ), proportion of extension to the circumference of the lumen $(<3 / 4,90.1 \%$ vs $45.5 \%$; $\geq 3 / 4,9.4 \%$ vs $54.5 \%)$ and longitudinal extent of mucosal defect $(27.9 \pm 10.1 \mathrm{~mm}$ vs $51.5 \pm 10.8$ $\mathrm{mm}$ ) were found between the nonstricture and stricture groups, respectively.

\section{Risk factors for endoscopic dilatation}

All 11 patients who developed post-ESD stricture underwent successful endoscopic balloon dilatation without complications. The clinical characteristics of these patients are summarized in Table 3. Of these 11 patients, nine had an antral or pyloric deformity before ESD. Eight patients had antral or pyloric deformity of distortion dominant type and one patient had that of narrowing dominant type. The mean period from ESD to diagnosis of post-ESD stricture was $58.3 \pm 31.4$ days (range, 29 to 124 days). The median number of balloon dilatations used was 2.0 (range, 1 to 4). Balloon size during dilatation ranged from $13.5 \mathrm{~mm}$ to $20 \mathrm{~mm}$. All patients experienced relief of obstructive symptoms (i.e., nausea, vomiting, and dysphagia) after the procedure and required no further treatment.

Risk factors for post-ESD stricture were then analyzed. In the univariate analysis, the proportion of post-ESD bleeding, antral or pyloric deformity, the larger longitudinal extent of mucosal defect and a circumferential extension to the mucosal defect of $\geq 3 / 4$ in stricture group were significantly higher than the corresponding parameters in the nonstricture group. Multivariate analysis revealed that pretreatment antral or pyloric deformity

Table 2. Factors Associated with ESD Procedures

\begin{tabular}{|c|c|c|c|c|}
\hline \multirow{2}{*}{ Variable } & \multirow{2}{*}{ Total $(n=150)$} & \multicolumn{2}{|c|}{ Post-ESD stricture } & \multirow{2}{*}{ p-value } \\
\hline & & None $(n=139)$ & Present $(n=11)$ & \\
\hline Antral deformity & 74 (49.3) & 65 (46.8) & $9(81.8)$ & 0.025 \\
\hline Type of antral deformity & & & & 0.665 \\
\hline Distortion dominant & 66 (89.2) & $58(87.9)$ & $8(88.9)$ & \\
\hline Narrowing dominant & $6(8.1)$ & $5(7.7)$ & $1(11.1)$ & \\
\hline Mixed type & $2(2.7)$ & $2(3.1)$ & 0 & \\
\hline Longitudinal extent of mucosal defect, mm & $29.7 \pm 11.8$ & $27.9 \pm 10.1$ & $51.5 \pm 10.8$ & $<0.001$ \\
\hline Circumferential extent of mucosal defect & & & & 0.001 \\
\hline$\geq 3 / 4$ & 19 (12.7) & $13(9.4)$ & $6(54.5)$ & \\
\hline$<3 / 4$ & $131(87.3)$ & $126(90.1)$ & $5(45.5)$ & \\
\hline Resection included pyloric ring & & & & 0.249 \\
\hline Yes & $32(21.3)$ & $28(20.0)$ & $4(36.4)$ & \\
\hline No & $118(78.7)$ & $111(80.0)$ & 7 (63.6) & \\
\hline
\end{tabular}

Data are presented as number (\%) or mean \pm SD.

ESD, endoscopic submucosal dissection. 
Table 3. Clinical Characteristics of Patients Who Had Undergone Balloon Dilatation

\begin{tabular}{|c|c|c|c|c|c|c|c|c|c|}
\hline Patients & $\begin{array}{l}\text { Age/ } \\
\text { sex }\end{array}$ & $\begin{array}{c}\text { Antral/pyloric } \\
\text { deformity }\end{array}$ & $\begin{array}{l}\text { Type of antral/ } \\
\text { pyloric deformity }\end{array}$ & $\begin{array}{l}\text { Subcircumferential } \\
\text { extension over } 75 \%\end{array}$ & $\begin{array}{c}\text { Days before } \\
\text { diagnosis of } \\
\text { pyloric stricture }\end{array}$ & $\begin{array}{c}\text { No. of } \\
\text { dilatations }\end{array}$ & $\begin{array}{l}\text { Balloon } \\
\text { size, mm }\end{array}$ & Complication & $\begin{array}{l}\text { Further } \\
\text { treatment }\end{array}$ \\
\hline 1 & $66 / \mathrm{M}$ & Yes & Narrowing & No & 85 & 1 & $13.5-14$ & No & No \\
\hline 2 & 77/M & Yes & Distortion & No & 29 & 4 & $14-17.5$ & No & No \\
\hline 3 & 75/M & No & - & Yes & 42 & 2 & $15-20$ & No & No \\
\hline 4 & $63 / \mathrm{M}$ & Yes & Distortion & Yes & 40 & 1 & $18-20$ & No & No \\
\hline 5 & $80 / \mathrm{M}$ & Yes & Distortion & No & 124 & 1 & 18 & No & No \\
\hline 6 & $77 / \mathrm{M}$ & Yes & Distortion & No & 30 & 1 & 18 & No & No \\
\hline 7 & $72 / \mathrm{M}$ & Yes & Distortion & Yes & 70 & 4 & $16.5-18$ & No & No \\
\hline 8 & 71/M & Yes & Distortion & Yes & 29 & 4 & 18 & No & No \\
\hline 9 & $84 / \mathrm{M}$ & Yes & Distortion & Yes & 38 & 1 & 20 & No & No \\
\hline 10 & 71/M & Yes & Distortion & No & 62 & 3 & 18 & No & No \\
\hline 11 & $74 / \mathrm{M}$ & No & - & Yes & 92 & 1 & 20 & No & No \\
\hline
\end{tabular}

$\mathrm{M}$, male.

Table 4. Multivariate Analysis of Risk Factors for Post-ESD Stricture

\begin{tabular}{lrll}
\hline \multicolumn{1}{c}{ Factor } & \multicolumn{1}{c}{ OR } & \multicolumn{1}{c}{ 95\% CI } & p-value \\
\hline Age, yr & 0.99 & $0.849-1.147$ & 0.863 \\
Antral/pyloric deformity & 30.53 & $1.476-631.565$ & 0.027 \\
Longitudinal extent of mucosal defect, mm (mean \pm SD) & 1.20 & $1.074-1.340$ & 0.001 \\
Circumferential extent of mucosal defect, >3/4 & 13.69 & $1.583-118.387$ & 0.017 \\
Post-ESD bleeding \& additional APC & 1.76 & $0.118-26.442$ & 0.681 \\
\hline
\end{tabular}

OR, odds ratio; CI, confidence interval; ESD, endoscopic submucosal dissection; APC, argon plasma coagulation.

(odds ratio [OR], 30.53; 95\% confidence interval [CI], 1.476 to 631.565; $\mathrm{p}=0.027$ ), a larger longitudinal extent of mucosal defect (OR, 1.20; 95\% CI, 1.074 to $1.340 ; \mathrm{p}=0.001)$, and circumferential extension of $\geq 3 / 4$ (OR, 13.69; 95\% CI, 1.583 to 118.387 ; $\mathrm{p}=0.017$ ) were independent risk factors for post-ESD stricture (Table 4).

\section{DISCUSSION}

ESD is established as a standard treatment in many patients with gastric tumors. ESD is minimally invasive, preserves postoperative gastric function, and has an efficacy similar to that with surgery. ${ }^{1,2,9,10}$ Because of the expanded indications of EGC and technical improvements, the number of patients with gastric neoplasms undergoing ESD is increasing. ${ }^{9-13}$ Accordingly, the number of resection-related complications such as massive bleeding, perforation, and stricture is also increasing. ${ }^{14,15} \mathrm{Al}-$ though the safety of ESD has been demonstrated, it is technically challenging and requires a well-trained endoscopist who must be aware of the incidence and risk factors of resectionrelated complications.

Post-ESD stricture is a delayed complication of the procedure and a second treatment may be needed if post-ESD stricture develops. Therefore, awareness of the risk factors for post-ESD stricture before ESD is important, and patients at increased risk should be followed up more closely following ESD. To the best of our knowledge, our study results are the first to show that antral or pyloric deformity is a risk factor for post-ESD stricture, as well as circumferential extension over 75\%.

Bleeding and perforation are the most common complications and tend to occur during or within 24 to 48 hours after ESD, ${ }^{14-16}$ whereas post-ESD strictures occur after several weeks. Cases of bleeding and perforation after ESD have been reported, and treatment procedures such as endoscopic hemostasis for bleeding and endoscopic clipping or surgical treatment for perforation are well accepted. ${ }^{14,15}$ However, there are relatively few reports about post-ESD stricture and its treatment. ${ }^{6,7,17,18}$

The reported incidence of post-ESD stricture is $0.7 \%$ to $1.9 \%$, ${ }^{14}$ and the incidences of post-ESD stricture in the cardia and pylorus are $17 \%$ and $7 \%$, respectively. ${ }^{6}$ A small number of case reports describing post-ESD stricture and treatment have been published, ${ }^{17,18}$ along with two previous studies on the risk factors for post-ESD stricture. ${ }^{6,7}$ Both previous investigations reported that a circumferential extension over 75\% and a larger longitudinal diameter were risk factors for development of post-ESD strictures. ${ }^{6,7}$ Coda et al. ${ }^{6}$ reported that a circumferential extent of 
the mucosal defect over 75\% or longitudinal extent greater than $5 \mathrm{~cm}$ in length were both risk factors for post-ESD stricture in patients undergoing cardiac and pyloric resection. Izuka et al. ${ }^{7}$ noted that a circumferential extent over 75\% was a risk factor for post-ESD stricture in six cases. However, post-ESD stricture can occur frequently even if the circumferential extension is $<75 \%$ with a longitudinal extent $<5 \mathrm{~cm}$, for example, in the presence of antral or pylorus deformity before ESD.

The present study investigated the impact of antral or pyloric deformity on the development of post-ESD strictures. Similar to previous studies, we showed that a circumferential extension of $\geq 3 / 4$ (OR, 13.69; 95\% CI, 1.583 to $118.387 ; \mathrm{p}=0.017$ ) and a larger longitudinal extent of mucosal defect (OR, 1.20; 95\% CI, 1.074 to $1.340 ; p=0.001$ ) were risk factors for post-ESD stricture. Moreover, antral or pyloric deformity prior to treatment (OR, 30.53; 95\% CI, 1.476 to 631.565; $\mathrm{p}=0.027$ ) was also an independent risk factor for post-ESD stricture. Among the 11 patients in the stricture group, nine $(81.8 \%)$ had an antral or pyloric deformity while two (18.2\%) did not.

Antral or pyloric deformity such as narrowing and distortion is usually caused by peptic ulcer scarring. ${ }^{8,19}$ ESD can cause a large artificial ulcer with gastric deformities during the healing process. Because artificial ulcers caused by ESD are formed suddenly and are confined to the superficial layer, they are reported to decrease in size with adjacent regenerative mucosa during healing. ${ }^{18}$ In the presence of a gastric deformity before ESD, pyloric stricture can worsen. Recognizing risk factors of post-ESD stricture before ESD is very important. Because endoscopist can perform local steroid injection into the artificial ulcer after ESD to prevent post-ESD stricture. In previous study, local injection of TCA into the large artificial ulcer following ESD may prevent post-ESD gastric deformity. ${ }^{20}$ Therefore, the endoscopist should be aware of the risk of post-ESD stricture in patients with antral or pyloric deformity.

In our study, the rate of post-ESD bleeding was higher in stricture group compared with nonstricture group. Seven cases of post-ESD bleeding were treated by endoscopic hemostasis using argon plasma coagulation (Erbe Elektromedizin). Additional APC at post-ESD ulcer could damage a muscle layer of postESD ulcer and pyloric stricture could worsen. However, in the multivariate analysis of risk factors for post-ESD stricture, postESD bleeding and additional APC was not a significant risk factor. Further large, multicenter trials could be necessary about long term adverse events after post-ESD bleeding and additional treatments.

Balloon dilatation is effective in enlarging strictures that form after ER and at the site of anastomosis following esophagectomy or gastrectomy. ${ }^{21}$ Balloon dilatation is also considered as standard treatment for benign strictures caused by pathologies such as corrosive esophagitis and peptic gastric outlet obstruction. As seen in the present series of cases, balloon dilatation is also an effective treatment for post-ESD stricture. ${ }^{6,722}$ A previous study reported on 14 cases of post-ESD stricture and outcomes of balloon dilatation compared with peptic strictures. ${ }^{18}$ Although the safety of balloon dilatation has been demonstrated, it can be associated with procedure-related complications such as massive bleeding and perforation. Severe stricture and fibrosis can also develop after ESD during the healing phase. The risk of perforation during balloon dilatation is related to the stricture and fibrosis of the stomach wall. To lower the risk of perforation, intervention should be carried out as soon as possible, before the appearance of severe fibrosis. This can be achieved by close monitoring of patients at higher risk during follow-up. Nonetheless, post-ESD stricture can recur even though balloon dilatation is successful, and repeat balloon dilatation is considered as standard treatment for recurrent cases. The coexistence of deformity and post-ESD scarring can lead to more severe fibrosis and stricture during healing. Consequently, endoscopists must be aware that patients with larger subcircumferential extension over 75\%, a larger longitudinal extent of mucosal defect and/or antral or pyloric deformity are at greater risk for postESD stricture. Such patients warrant close follow-up so that intervention can be performed as early as possible.

Our study has several limitations. First, we could not analyze the efficacy of local steroid injection because of small number. In our study, only two patients underwent prophylactic local TCA infection 1 to 2 days after ESD. Second, the study was a retrospective analysis and had a relative small sample size. However, the ESD data were prospectively collected in our institute to minimize the chance of bias. Further multicenter trials could validate the results seen herein.

In conclusion, this study found that the presence of antral or pyloric deformity is one of the important risk factors for postESD stricture. Patients with deformities before ESD should be carefully followed up and treated by local steroid injection therapy or endoscopic balloon dilatation at an early stage to prevent post-ESD stricture.

\section{CONFLICTS OF INTEREST}

No potential conflict of interest relevant to this article was reported.

\section{REFERENCES}

1. Chung MW, Jeong O, Park YK, et al. Comparison on the long term outcome between endoscopic submucosal dissection and surgical treatment for undifferentiated early gastric cancer. Korean J Gastroenterol 2014;63:90-98.

2. Gotoda T. Endoscopic resection of early gastric cancer. Gastric Cancer 2007;10:1-11.

3. Gotoda T, Yamamoto H, Soetikno RM. Endoscopic submucosal dissection of early gastric cancer. J Gastroenterol 2006;41:929942. 
4. Gotoda T, Yanagisawa A, Sasako M, et al. Incidence of lymph node metastasis from early gastric cancer: estimation with a large number of cases at two large centers. Gastric Cancer 2000;3:219225.

5. Hirasawa T, Gotoda T, Miyata S, et al. Incidence of lymph node metastasis and the feasibility of endoscopic resection for undifferentiated-type early gastric cancer. Gastric Cancer 2009;12:148-152.

6. Coda S, Oda I, Gotoda T, Yokoi C, Kikuchi T, Ono H. Risk factors for cardiac and pyloric stenosis after endoscopic submucosal dissection, and efficacy of endoscopic balloon dilation treatment. Endoscopy 2009;41:421-426.

7. Iizuka H, Kakizaki S, Sohara N, et al. Stricture after endoscopic submucosal dissection for early gastric cancers and adenomas. Dig Endosc 2010;22:282-288.

8. Tawile N, Schuman BM. A gastroscopic analysis of antral deformity. Gastrointest Endosc 1974;20:160-161.

9. Gotoda T, Ho KY, Soetikno R, Kaltenbach T, Draganov P. Gastric ESD: current status and future directions of devices and training. Gastrointest Endosc Clin N Am 2014;24:213-233.

10. Oka S, Tanaka S, Higashiyama M, et al. Clinical validity of the expanded criteria for endoscopic resection of undifferentiated-type early gastric cancer based on long-term outcomes Surg Endosc 2014;28:639-647.

11. Abe S, Oda I, Suzuki H, et al. Short- and long-term outcomes of endoscopic submucosal dissection for undifferentiated early gastric cancer. Endoscopy 2013;45:703-707.

12. Ahn JY, Jung HY. Long-term outcome of extended endoscopic submucosal dissection for early gastric cancer with differentiated histology. Clin Endosc 2013;46:463-466.

13. Park CH, Shin S, Park JC, et al. Long-term outcome of early gastric cancer after endoscopic submucosal dissection: expanded indication is comparable to absolute indication. Dig Liver Dis 2013;45:651-656.
14. Ojima T, Takifuji K, Nakamura M, et al. Complications of endoscopic submucosal dissection for gastric noninvasive neoplasia: an analysis of 647 lesions. Surg Laparosc Endosc Percutan Tech 2014;24:370-374.

15. Okada K, Yamamoto Y, Kasuga A, et al. Risk factors for delayed bleeding after endoscopic submucosal dissection for gastric neoplasm. Surg Endosc 2011;25:98-107.

16. Yoshio T, Nishida T, Kawai N, et al. Gastric ESD under heparin replacement at high-risk patients of thromboembolism is technically feasible but has a high risk of delayed bleeding: Osaka University ESD Study Group. Gastroenterol Res Pract 2013;2013:365830.

17. Mori H, Kobara H, Fujihara S, Nishiyama N, Rafiq K, Masaki T. Recanalization of severe gastric antral stricture after large endoscopic submucosal dissection: mucosal incision and local steroid injection. J Gastrointestin Liver Dis 2012;21:435-437.

18. Na HK, Choi KD, Ahn JY, et al. Outcomes of balloon dilation for the treatment of strictures after endoscopic submucosal dissection compared with peptic strictures. Surg Endosc 2013;27:3237-3246.

19. Geffen A, Feldman F. Antral deformity due to perigastric adhesions or bands simulating carcinoma of the stomach. Radiology 1961;77:237-247.

20. Mori H, Rafiq K, Kobara H, et al. Local steroid injection into the artificial ulcer created by endoscopic submucosal dissection for gastric cancer: prevention of gastric deformity. Endoscopy 2012; 44:641-648.

21. Isomoto H, Yamaguchi N, Minami H, Nakao K. Management of complications associated with endoscopic submucosal dissection/ endoscopic mucosal resection for esophageal cancer. Dig Endosc 2013;25 Suppl 1:29-38.

22. Kabashima A, Kitagawa D, Nakamura T, et al. Case of early antral gastric cancer diagnosed during follow up of pyloric stenosis by the gastro-duodenal ulcer. Fukuoka Igaku Zasshi 2013;104:589594. 